\title{
Sustainability and Public Engagement in Mining: The Role of Engineers
}

\author{
Marcello M. Veiga and Christopher Tucker \\ Norman B. Keevil Institute of Mining Engineering, University of British Columbia, Vancouver V6T1Z4, Canada
}

\begin{abstract}
Social issues are increasingly recognized as significant inhibitors to mineral development projects. Increasingly, social risk is being recognized as a key factor determining the success of a mineral investment. Groups opposed to a mine for social or political reasons often use environmental impacts, real or perceived, to prevent mine development. These risk factors depend largely on cultural perceptions of mining activities and must be understood as such in order to be appropriately managed. A first step to addressing social issues is inclusive, transparent and meaningful engagement of stakeholders. This process allows stakeholders to understand what the other parties value in order to collectively establish a common currency for development and the creation of mutual value. Expanding the scope of benefits and values a mine can bring is of increasing importance to mining companies who typically consult outside specialists remote from the mine site and late in the development timeline for this purpose. Training technical staff, engineers and geologists, who make initial and ongoing contact with local interests, in a holistic approach to mine development is crucial to successful and economic mineral development projects. Further extending this conversation to the general public, media governments and non-governmental organizations is a necessary step in developing a meaningful discourse on the benefit of mining activities.
\end{abstract}

Key words: Social issues in mining, mining and society, public engagement, sustainability of mining.

\section{Social Issues in Mining}

The public often perceives mining operations as causing serious adverse problems to both environmental and human health. Past examples of poor performance in handling environmental and human rights issues linger in the social memory and haunt new mineral development proposals. In such cases, opponents to mineral development will often cite environmental issues such as the potential legacy of pollution left by a mine, destruction of surrounding lands and forests, water contamination and depletion, loss of access to recreational or traditional lands, noise, dust, and excessive truck traffic.

Environmental impacts of most mining operations are localized and relatively small compared to many other forms of human economic activity such as agriculture, forestry and urban settlement. Nonetheless

Corresponding author: Marcello M. Veiga, professor, research fields: artisanal mining, sustainability in mining, metals in the environment, recycling, mercury pollution and social issues in mining. E-mail: veiga@mining.ubc.ca. mining can negatively impact the environment especially if not well managed. More frequently companies around the world are facing problems with local communities and international environmental groups when implementing mining projects [1]. Environmental issues are often used to justify the opposition when in fact, there are larger unresolved social and/or political problems or such as the case where the initial approach of the mining company was not well received by the communities. Typically a mining company limits the focus of their perception and communication of community benefits to taxation revenues and job creation. The veracity of this position is challenged in the notion of the resource curse [2] where it is argued that countries endowed with great mineral or petroleum wealth do not see a corresponding increase in the well-being of their people with the development of those resources. As with critics of aid programs [3], resource-rich countries often see their governance structures and sovereignty challenged rather than strengthened. One 
rationale for the unsustainable extraction of non-renewable resources is when this activity can support the development of sustainable and sustaining improvements in other areas of human wealth. For example, sustainable mining, considered by many to be an oxymoron can be used to describe the extraction of mineral resources in a manner that contributes to long-lasting wealth or wellbeing.

Numerous levels of human organization may be considered for wealth creation. It is possible to look at this globally, internationally or nationally. In the latter case, financial vehicles such as Norway's Sovereign Wealth Fund borne out of Norway's North Sea oil extraction, can be used to create lasting well-being among a people where inclusion boundaries are clear, in this case, citizenship [4]. At a provincial or state level similar vehicles exist such as the less successful Alberta Heritage Fund designed to provide lasting benefit from the wealth created by Tar Sands development in Canada or even the various credits issued by local taxation authorities [5]. At the regional, municipal and community level, where inclusion boundaries are more porous, it is more difficult to manage distribution of benefits from resource development. As resources such as oil and gas or minerals are often more locally situated extending their benefits locally makes sense. In this case it can make sense that the benefits rather than being financial in nature are themselves locally distributed in ways such as infrastructure improvements or local quality of life enhancements. The most effective level for creating to create real improvements in human wellbeing is at the community level, where a community is defined as a local grouping of people with some commonality in strategies for meeting their needs. Many different types of communities participate in non-sustainable practices in order to meet their needs and potentially all could improve their way of life while decreasing their dependency on imperiled resources, whether they be old growth forests, wild salmon, cheap oil, or high grade gold and copper deposits.

\section{The Changing Role of the Engineer}

Engineers usually define the steps of a "Mining Project" using technical-economic parameters that can be simplified in "8 Ds":

(1) Detection of geological anomalies;

(2) Discovery of the mineral deposit;

(3) Definition of the ore body to be mined;

(4) Design of the mine;

(5) Decision to go ahead with the project;

(6) Development of the mine;

(7) Depletion of the ore body;

(8) Decommissioning of the mine.

This mnemonic sequence of "Ds" does not consider that quite often another " $D$ " happens: deception, which is usually caused by the lack of an interdisciplinary approach or lack of understanding of the socio-economic environment in which a mining project is implemented. In the past, environmental and social issues were ignored or approached at the very end of a mining project to fulfill legal exigencies. Many mining proposals have failed because mining companies did not believe that it was their responsibility to deal with the local stakeholders in the early stages of a project [6]. The lack of social license to operate has been recently stressed as one of the major hurdles for the mining companies to start a project [7]. Even when the company has an environmental permit, the public perception of the mine, associated with hidden political interests, prevents the project realization. For example in the case of Infinito Gold, in Costa Rica, a project that would have created a large number of jobs for the local community in diversified activities could not sail through because strong political players associated with international NGOs, scared the local people alleging that tailing dam failures will "lead to water contamination and landslides" [8]. This is also the case of Marlin Mine in Guatemala where many environmentalists believe that the population is 
vulnerable to cyanide spills, despite the total destruction and regeneration of the cyanide used in the mine [9].

In 2014, in British Columbia, Canada, Taseko Mines had its New Prosperity project rejected for the second time. First Nation leaders in the region opposed the project, alleging it would threaten the environmental integrity of Fish Lake, a $1 \mathrm{~km}^{2}$ productive lake in the remote region of Cariboo-Chilcotin. The project would have generated around US $\$ 10$ billion in taxes directly and indirectly had the potential to generate 3,000 new jobs. The Federal Government, through two Assessment Panels, predicted environmental impacts for the lake [10]. For the general public and governments, the environmental argument was the main reason given for the project rejection, but it seems secondary in the decision process as the First Nations regard the lake as sacred and the relationship between the company and First Nations degenerated upon the failure to establish a working joint review panel [10]. All activities of the company to mitigate the environmental impacts and to preserve the lake were not enough to bring the public opinion to their side. In this situation both parties, initially willing to do business, could not find a common "currency" by which to create mutual value, resulting in a breakdown of the relationship.

The above examples illustrate the importance of effective early engagement with communities. As technical people, such as geologists and engineers, are often the point of first (and ongoing) contact, it is imperative that they have an understanding of the social dimensions of their work. Frequently social issues are delegated to social scientists hired as consultants to establish a strategy to deal with the local communities. The plans may be well done but the execution will still be in the hands of technical staff permanently present at the mining site. Rarely do engineers regard understanding social factors as part of their professional capacity. They typically fail to understand the traditions, cultures and idiosyncrasies of the local communities. This lack of understanding can lead to roadblocks and demonstrations by local community members that effectively halt production and ties up management, leading to serious cost overruns [1].

Most mining engineers have perceived education on social issues related to natural resources as a topic of secondary importance. Unfortunately, this is a common situation in the technical academic world. Even now, when the mining industry is being monitored by media, stakeholders and non-governmental organizations, few academics bring the socio-political context to the engineering classrooms. The role of mining in promoting development and reducing poverty has been challenged, since there is no clear indicator of success [11]. The most significant criticisms relate to the attitudes and performance of the mining companies in the field.

Some engineers still believe that the misunderstanding between companies and communities must be resolved with legal interventions or they simply apply the philanthropic approach of providing immediate benefits to the locals. In first place, rural communities around the world typically have little faith in political systems as their politicians only appear when there is an election. Rural communities have been relatively isolated for centuries, without political clout, receiving few benefits only from central governments. This is the case with the town Paraupebas with 110,000 inhabitants in the Brazilian Amazon, near the Vale's gigantic Carajás Project. Mining activities in the Carajás Ore District are responsible for $70 \%$ of Paraupebas' Gross Domestic Product. In 2000, the municipal government received US \$12 million from royalties of the iron-ore mining alone, which is a fraction of the taxes from all the mines in the region. Despite the high incomes of the municipal government, about $44 \%$ of the total population lives below the poverty line, the infant mortality is 30 
deaths per 1,000 inhabitants per annum, hospitals have 1.6 beds per 1,000 inhabitants and various other indicators do not show much in the way of the benefits to the town from the largest mining complex in the world [12]. Clearly the wealth from the mines is not distributed to the community. The lesson learned in many rural communities is: "the closer the company is to the government, the farther they are from the local community."

The main challenge of mining companies is to engage in equitable partnership with the impacted community to create a sustainable relationship [13]. This is usually seen as a secondary task to be left with a department of public relations. All technical staff in a mine must be trained to participate in the community and engage the population in the decision process, even if this is a very technical subject. It is not a matter of communication, but engagement.

\section{Public Engagement}

Problems with local communities are not only caused by lack of planning of the companies. Planning usually takes place in corporate headquarters remote from the mine site and in many cases the companies use local employees to implement their policies. In many instances, this is seen as a communication problem, when in fact it is a lack of participation of the locals in the decision process [14].

It is well established that mining companies have a legal duty to consult local communities. However, the term "consultation" does not ensure an open dialogue or a participatory process. Social License to operate describes a dynamic of engagement over and above legally bound consultation that is necessary for a development to have the support of local communities.

Companies must account for their actions and the local communities and the general public require transparency and inclusion in the decision making process. "Organizational accountability is based on effective engagement with stakeholders" [15]. The practice of hiding mistakes from the local community is no longer accepted.

In communicating with local communities, engineers often use facts to explain their actions. Different stakeholders come with different levels of understanding about how a mine is built and operated. These different knowledge bases combined with different value systems produce radically different perceptions about the process of mine development. The perceptions of the communities, usually in rural areas with low education, cannot be resolved with a list of facts. Technical facts may be obvious for engineers but not clear for the public. Demonstrating that you are more knowledgeable, that you have the correct facts can even be more frustrating and detrimental to the process of building trust and consensus. Facts are not very useful in dealing with perceptions as they create a hierarchy in the debate and imply the superiority of the company. The best way to deal with perceptions of the public and local communities is to understand and attend to the sources of perceptions (Fig. 1). This can encourage dialogue and shift attitudes about the project.

An example of this is the most common argument presented by mining industry associations: "you need mineral products, therefore you need mining." While this is true and world consumption of minerals is around 5 tonnes/person/a, and in developed countries this can reach 20 to 50 tonnes/person/a and still growing [16], it is not a persuasive or compelling argument. Relying on this line of reasoning further fails to look at deeper social and cultural resistance to mining activity. With this tension unresolved, we see playing out in the media crude arguments for or against mining. The reality is that mineral development is not only required but also desirable while also posing risk and tradeoffs. Accepting that both perspectives are "true" allows a more sophisticated conversation that can more effectively manage the costs and benefits of the activity.

A common public perception in developing 


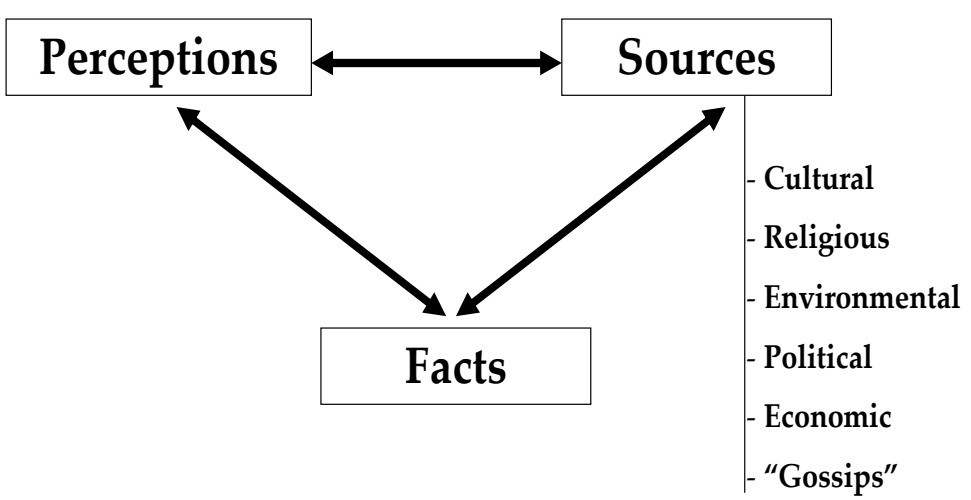

Fig. 1 Knowing the sources of perceptions is more important than facts.

countries is that foreign companies are extracting gold to take back to their home countries. Community expectations are awoken at the beginning of the exploration phase especially with regards to job creation. During the project discovery, development and implementation the community expectations fluctuate and can create conflicts with the company expectations. Ian Thomson developed the following graphic to show the lack of syntony between the company and community expectations (Fig. 2). The simple presence of drilling in the community can create high false expectations that the mining production will start soon. The time lag of the mining industry can be as large as 10 years from exploration to construction [17].

Benefits for rural communities are important as a palliative measure to release the immediate pressures of the local population, but in many cases they are not sustainable and tend to disappear once the mineral resources are depleted. Once the mine has closed, infrastructure that has been built for the community is rarely maintained, leaving empty hospitals and schools behind. Life skills, culture, friendship, and self-respect are values that are more sustainable than benefits, and can both benefit the community-company relationship as well as leave a lasting legacy. Companies are not prepared to diversify the communities they operate in, even over the long term. They usually believe that it is the responsibility of the government to use tax revenue obtained from the mine to accomplish these objectives.

Recently, the mining industry has realized that environmental and social issues are key to changing the public image as well as to establish a long and sincere relationship with local communities. A mine can be a "showcase" of environment-friendly operations, but if the social issues are not addressed (and vice versa), this can create lots of problems with the public. "Improving environmental performance is critical to ensuring that the environment is protected, but does not necessarily ensure the social health and welfare of any associated mining community during operation and after closure" [13].

There is no formula for dealing with public engagement, since in communities, there are different perceptions and emotions. It is important to identify in a community values, perceptions, historical facts and other potential sources of conflict.

\section{Sustainable Development in Mining}

The term "sustainable mining" has been used to call attention to the public and the mining industry to the fact that the non-renewable resources must be efficiently extracted, processed, used and recycled [18]. The community and the environment in which a mine operates must be sustained, and not the mine. The concepts of efficiency have usually been attached to the concept of sustainable development in industrial operation. However, sustainable development is an 


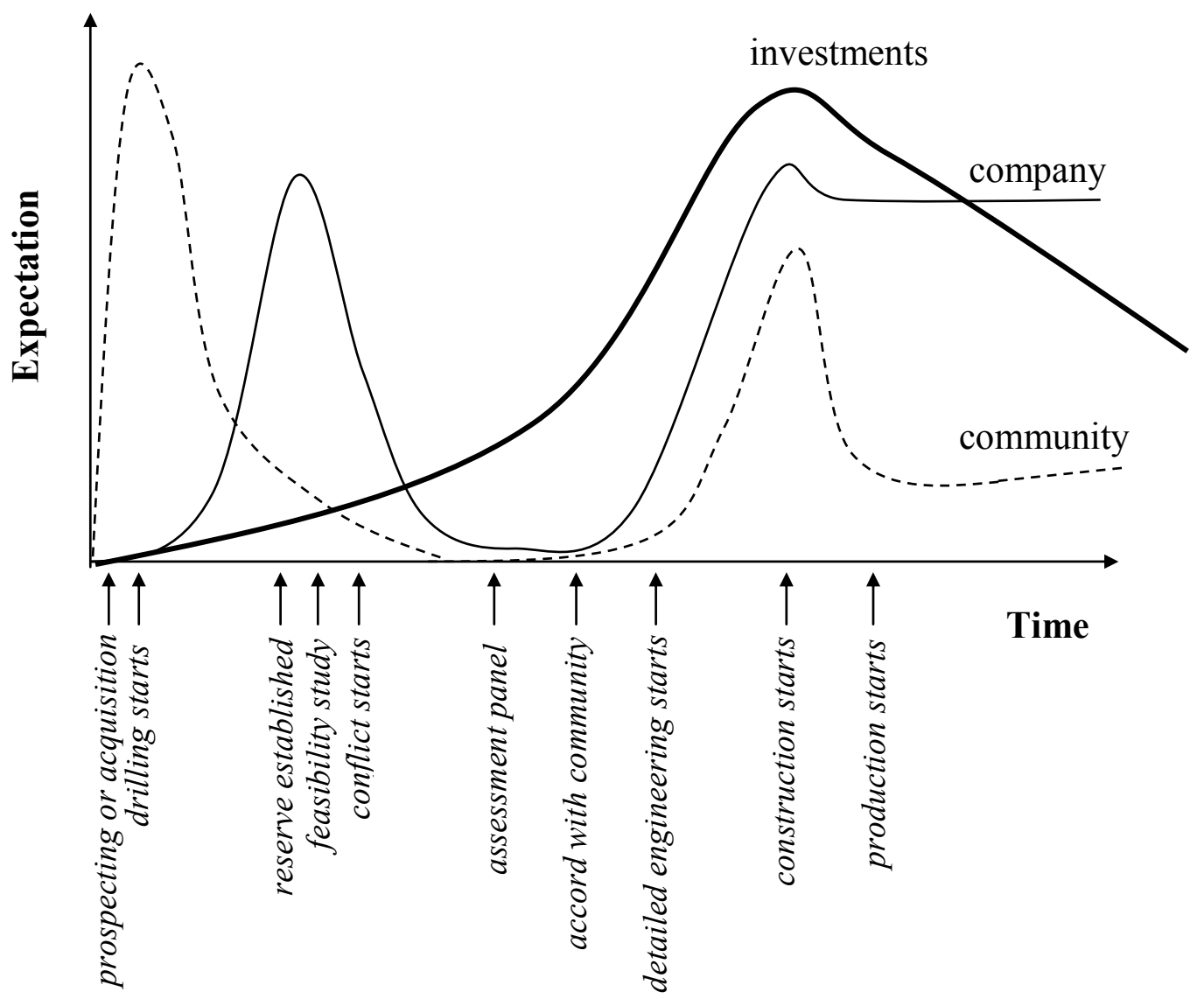

Fig. 2 Different expectations about a mining project (free adaptation of Ian Thomson's idea).

ethical concept that is attached to "economic prosperity, environmental health, and social equity for the benefit of current and future generations" [19]. According to George Francis, professor of Environmental Studies at University of Waterloo, "sustainability is ultimately an ethical commitment based on a belief that the natural world and its component life forms, including humanity, have value in and for themselves" [13]. Even in the official UN document in which Sustainable Development was conceptualized [20], the definition makes reference to an ethical commitment to leave resources for the next generations: "...development that which satisfies present needs without compromising the possibility for future generations to satisfy theirs" [21].

According to Kazakidiset al. (2013) [22], "sustainable development issues, are often at the centre of a dispute that can make an empowered local community or group in a first world country the strongest stakeholder in a new mineral resource development (either as advocates or opponents)". In fact, nowadays the environmental and social arguments mix and are hard to divorce even in legal terms, when a judicial dispute is taking place. The example of Prosperity Mine shows this clearly. Taseko Mines tried to implement a mine dumping tailings in a fish-rich lake. The idea to transport the entire population of fish to an artificial lake was opposed by the First Nations, by the time the company tried another more environmentally "acceptable" solution, the relationship with locals had already deteriorated.

The question is how to implement concepts of sustainable development into a mining operation. As mining operations occur in remote areas, the main challenge of the companies is to deal with impoverished communities that the only contact they had with mining was probably with artisanal mining. In Tambogrande, Peru, for example, the community 
expelled a mining company that wanted to develop a mine and was accused of generating pollution that would affect agriculture in the valley. Around $87 \%$ of the population with households in the town opposed to the project [23]. Now the town is invaded by artisanal miners dumping mercury and sediments into the local rivers. In the Piura region 10,000 miners and more that 160 processing plants are dispersed in 158,000 ha applying extremely primitive techniques to extract gold [24]. For the community, this is acceptable since artisanal mining generates more jobs for unskilled people than a conventional mine. However, sustainable benefits of a mining activity, artisanal mining cannot provide. This is observed in thousands of shanty villages in the Brazilian Amazon created during the gold rush of artisanal miners and now they have no economic alternatives [25]. Artisanal mining is regarded by most rural communities as the easiest and fastest way to getting out of extreme poverty, while the immediate environmental impacts are disregarded by the desperately poor local communities. A similar problem occurs when a developing or operating mine is a community's sole source of income. A mine represents an opportunity to add value to a community. Traditionally, mines are said to contribute to communities through direct employment, ancillary economic activity that supports the mine, infrastructure investment, educational programs and scholarships, as well as recreational facilities. Benefits such as these are important but not sustainable either in conventional or in artisanal mining. After the mine closure most towns remain without the benefits. Towns left behind by mining companies become ghost towns. The mining companies have very little participation in helping communities in their economic diversification, i.e. to find alternatives after mining. Mining companies rarely provide useful land use (reclamation) for community use; most reclamation objectives are for wildlife. Beyond that, companies need to think about how a new mine can bring long term biophysical and socio-economic improvement to a region which is consistent with holistic principles of sustainability. The legacy left by a mine to the community after its closure is emerging as a significant consideration in its planning. In these cases, the company must collaborate with the community to find solutions to diversify their economy and to leave behind sustainable benefits.

An important step to establish a good and sustainable relationship with the community is to recognize its values. Benefits are important, but values are sustainable (Table 1). When the ore is depleted and the company closes the mine, the communities are left with hospitals without doctors, school without teachers, and infrastructure without maintenance [26].

The first step to introduce concepts of sustainability in a mining community may relate to local capacity-building and local governance [13]. Local governance can achieve several benefits including actively involving local residents in the process of making decisions, reinforcing community self-esteem, bringing creativity for new opportunities, and reinforcing the relationship with the mining company.

Local governance is established with education and dialogue. When a community member is able to speak freely with a mining authority or a company representative, dialogue can be established and viewpoints understood. Co-development of projects to improve the interaction of a mine with the community and surrounding environment can help improve community relations:

- reduce tailing generation;

- increase metallurgical recoveries (mining and processing);

- recycle materials;

- find uses for tailings (bricks?);

- reduce energy and materials consumption;

- mine other things (garbage, sewage, thermal energy);

- think holistically (and beyond the mining operation);

- assist and participate in community projects. 
Table 1 Values and benefits a mining project can bring to the local community.

\begin{tabular}{ll}
\hline Human values & Benefits \\
\hline Friendship & Employment \\
Solidarity & Schools \\
Family & Hospitals \\
Culture \& Traditions & Paved roads \\
Respect & Clean water \\
\hline
\end{tabular}

Some argue that it is the role of government to assist the local communities through the investment of mining royalties. However, companies working in rural areas of developing countries are aware that the royalties are not always well administrated by local or regional governments and at the end of mine life the populations have no sustainable benefits. "A corollary of [the resource curse] is the neglect of the competitive diversification of the non-mining tradeables such as agriculture and manufacturing" [2]. As government policies are not sustainable, especially in developing countries, companies must create mechanisms to establish projects with the local communities to diversify their economy. This is the case for example of Sullivan Mine in Kimberley, BC. The mine operated from 1909 to 2001 and the city of Kimberly was incorporated in 1944. In total it has produced: 9 million tonnes of $\mathrm{Pb}, 9$ million tonnes of $\mathrm{Zn}, 280$ million oz Ag, \$20 billion in revenue. After a temporary closure in 1991, the community realized its dependency on mining and thanks to the leadership of the Mayor they started a public consultation to decide about the future of the town. After many debates the community decided to transform the town in a tourist destination. The town is today known as the Bavaria of the Canadian Rockies and has a steady flux of tourists to their golf courses and ski hills [27].

\section{Conclusions}

The social, economic, cultural, and physical effects of mineral development projects need to be understood at a much greater level by not only local stakeholders including technical staff but also the general public. Meaningful, inclusive decision making on resource projects requires innovative approaches to mining and exploration education as well as broader communication initiatives. Real and lasting value from mineral development derives largely from developing human infrastructure or social capital and values; this in turn depends on developing a sophisticated program of engagement with the community by numerous agencies including governments and mining companies.

\section{References}

[1] Davis, R., and Franks, D. M. 2011. "The Costs of Conflict with Local Communities in the Extractive Industry." In Proceedings of the First International Seminar on Social Responsibility in Mining, Santiago, Chile, Vol. 30.

[2] Auty, R. M. 1993. "Sustaining Development in Mineral Economies." The Resource Curse thesis, London, Routledge, 272.

[3] Moyo, D. 2009. Dead Aid: Why Aid Is Not Working and How There Is Another Way for Africa. New York: Farrar, Straus and Giroux, 209.

[4] Gjessing, O. P. K., and Syse, H. 2007. "Norwegian Petroleum Wealth and Universal Ownership." Corporate Governance: An International Review 15 (3): 427-37.

[5] Murphy, R. P. 2013. Reforming Alberta's Heritage Fund: Lessons from Alaska and Norway. Vancouver: Fraser Institute, 47.

[6] Owen, J. R., and Kemp, D. 2012. "Assets, Capitals, and Resources: Frameworks for Corporate Community Development in Mining." Business \& Society 51 (3): 382-408.

[7] Moffat, K., and Zhang, A. 2014. "The Paths to Social Licence to Operate: An Integrative Model Explaining Community Acceptance of Mining." Resources Policy 39: 61-70.

[8] Evans, M. 2012. Canadian Mining Company in Costa Rican Legal Storm. Costa Rica Star. $\mathrm{http} / /$ news.co.cr/canadian-mining-company-in-costa-rica n-legal-storm/16674/ Accessed April 19, 2014.

[9] Jaccard, H., and Condon, G. 2013. Guatemalans Resist Invasion of North American Mines. www.globalresearch.ca/guatemalans-resist-invasion-of-n orth-american-mines/5318080. Accessed April 14, 2014.

[10] CEAA. 2013. Canadian Environmental Assessment Agency. Report of the Federal Review Panel-New Prosperity Gold/Copper Mine Project. Oct 31, 2013.

[11] Pegg, S. 2006. "Mining and Poverty Reduction: Transforming Rhetoric into Reality." J. Cleaner Production 14: 376-87. 
[12] Costa, S. D. 2008. "Mineworkers' Quality of Life in Remote Communities: A Multiple Case Study in the Brazilian Amazon." Ph.D. thesis, Dept of Mining Engineering, University of British Columbia, 299, https://circle.ubc.ca/handle/2429/802. Accessed Jan. 30, 2014.

[13] Veiga, M., Scoble, M., and McAllister, M. L. 2001. "Mining with Communities." Natural Resources Forum 25 (3): 191-202.

[14] Prno, J. 2013. "An Analysis of Factors Leading to the Establishment of a Social Licence to Operate in the Mining Industry." Resources Policy 38 (4): 577-90.

[15] Petersen, F. W., and Bullock, S. E. T. 2005. "Sustainable Development Indicators-Some Technological Changes Made in the South African Mining and Resources Sector to Meet the Challenge." In A Review on Indicators of Sustainability for the Minerals Extraction Industries, edited by Villas Bôas, R. C., Shields, D., Šolar, S., Anciaux, P., and Önal, G. CETEM/MCT/ CNPq/CYTED/IMPC, Rio de Janeiro, 230.

[16] Jones, M. P. 1987. Applied Mineralogy, London, Ed. Graham \& Trotman, p. 259.

[17] Aboriginal Affairs and Northern Development Canada, Minerals \& Petroleum Resources Directorate. 2007. Stages of Mineral Exploration \& Development.

[18] Fitzpatrick, P., Fonseca, A., and McAllister, M. L. 2011. "From the Whitehorse Mining Initiative towards Sustainable Mining: Lessons Learned." J. Cleaner Production 19 (4): 376-84.

[19] Shields, D. J. 2005. USA and UN Perspectives on Indicators of Sustainability for the Mineral Extraction Industry. In A Review on Indicators of Sustainability for the Minerals Extraction Industries, edited by Villas Bôas, R. C., Shields., D., Šolar, S., Anciaux, P., and Önal, G. CETEM/MCT/ CNPq/CYTED/IMPC, Rio de Janeiro, 230 .
[20] Brundtland Commission, and Brundtl and Commission. 1987. Our Common Future.

[21] UN-WCED-United Nations World Commission on Environment and Development. 1987. Our Common Future. Oxford, UK: Oxford University Press.

[22] Kazakidis, V., Gaidajis, G., and Angelakoglou, K. 2013. "Evaluation of Environmental and Social Parameters of a Gold-Mining Project at the Prefeasibility Stage: A Case Study." Global Perspectives on Engineering Management 2 (2): 93-104.

[23] Muradian, R., Martinez-Alier, J., and Correa, H. 2003. "International Capital Versus Local Population: The Environmental Conflict of the Tambogrande Mining Project, Peru." Society \& Natural Resources 16 (9): 775-92.

[24] Veiga, M. M. 2014. Reducing Mercury Use and Release in Andean Artisanal and Small-Scale Gold Mining. Report to U.S. Department of State, Bureau of Oceans and International Environmental and Scientific Affairs Office of Environmental Policy, Mercury Program. Contract SLMAQM- 10-CA-312-RC, 79. (unpublished).

[25] Veiga, M. M. 1997. Introducing New Technologies for Abatement of Global Mercury Pollution in Latin America. Pub. UNIDO/UBC/CETEM. Rio de Janeiro, 94.

[26] Roberts, S., Veiga, M. M., Peiter, C. C., Sirotheau, G. J., Barreto, M. L., and Ezequiel, G. 2000. Filling the Void: The Changing Face of Mine-Reclamation in the Americas. Mine Closure: Iberoamerican Experiences. pp. 1-23. Villas-BOas, R. C. and Barreto, M. L. (Eds), Pub CYTED-IMACC/UNIDO, Rio de Janeiro, 456.

[27] Ednie, H. 2006. Creating a New Economy through Closure: Sullivan Mine Closure Sets the Barrier for Sustainable Practice. Retrieved April 20, 2014 from CIM website:

http://magazine.cim.org/en/May-2006/features-2/Creating -a-new-economy-through-closure.aspx. 